\section{Confirmation of New Crapemyrtle Bark Scale (Acanthococcus lagerstroemiae) Hosts (Spiraea and Callicarpa) through DNA Barcoding}

\author{
Runshi Xie and Bin Wu \\ Department of Horticultural Sciences, Texas A\&M University, College \\ Station, TX 77843; and Department of Biology, Texas A\&M University, \\ College Station, TX 77843
}

\author{
Mengmeng Gu \\ Department of Horticultural Sciences, Texas A\&M AgriLife Extension \\ Service, College Station, TX 77843
}

\author{
Stacey R. Jones \\ North Carolina Cooperative Extension, North Carolina State University, \\ Concord, NC 28027
}

James Robbins

Division of Agriculture, University of Arkansas, Little Rock, AR 72204

\begin{abstract}
Allen L. Szalanski
Department of Entomology, University of Arkansas, Fayetteville, AR 72701
\end{abstract}

\section{Hongmin Qin \\ Department of Biology, Texas A\&M University, College Station 77843}

Additional index words. alternative host, Crapemyrtle bark scale, Eriococcus, exotic scale insect, host range, phylogeny, species identification

\begin{abstract}
Crapemyrtle bark scale (CMBS; Acanthococcus lagerstroemiae Kuwana) is an invasive insect that was first discovered in the United States in 2004. The polyphagous feeding habit of CMBS has allowed it to infest a wide range of plant species beyond its primary host, Lagerstroemia. Using molecular approaches, we studied the genetic relationships between CMBS specimens and their hosts from different geographic locations. Naturally occurring CMBS infestations were confirmed on American beautyberry (Callicarpa americana $\mathbf{L}$.), a native plant species in the United States, and spirea (Spiraea L.). The new infestation of CMBS found on Spiraea raises the alarm that other economically important crops in the Amygdaloideae subfamily (subfamily under Rosaceae) might be susceptible to CMBS attacks.
\end{abstract}

Global trade and international travel have led to the establishment of invasive pests outside their native range. We have been following the distribution of CMBS [Acanthococcus lagerstroemiae (Kuwana)], an invasive insect first detected in the United States (in Texas) in 2004. To date, CMBS infestations have been reported in at least 17 states in the United States (EDDMapS., 2021). According to previous records, plant species from at least 22 genera (15 families) have been listed as

Received for publication 30 July 2021. Accepted for publication 20 Sept. 2021.

Published online 12 November 2021.

M.G. and H.Q. are the corresponding authors. E-mail: hqin@bio.tamu.edu or mgu@tamu.edu.

This is an open access article distributed under the CC BY-NC-ND license (https://creativecommons. org/licenses/by-nc-nd/4.0/).
CMBS hosts worldwide (García Morales et al., 2016). Since 2016, we have been conducting CMBS host range studies to confirm documented CMBS host plants from previous literature (worldwide) and to identify potential new CMBS host plants in the United States. Previous work by our group (Xie et al., 2020) confirmed apple (Malus domestica) as a host with moderate to severe susceptibility to CMBS.

Recent reports of naturally occurring CMBS infestations on alternative hosts are concerning. For instance, American beautyberry (Callicarpa americana) (Fig. 1A) and Hypericum kalmianum L. (St. Johnswort), both native species in the United States, were found to be infested with CMBS in the field (Wang et al., 2016) or horticultural plantings (Schultz and Szalanski, 2019). In 2019 and 2020, two incidents of scale infestation, later identified as CMBS, were reported on Spiraea japonica L.f. (University of Arkansas) (Fig. 1B) and S. thunbergii Sieb. Ex Blume (Concord, NC) (Fig. 1C).

Spiraea, commonly known as spirea or meadowsweet, is a genus of ornamental plants under the Rosaceae family. Approximately 100 to 120 Spiraea species were known worldwide and were primarily found in the temperate region of the northern hemisphere (Wrońska-Pilarek et al., 2019). Spiraea is one of eight genera under the Spiraeeae tribe (under subfamily Amygdaloideae) (USDA, 2021). The phylogeny of Rosaceae has revealed a closer relationship between Spiraeeae and Maleae (both under subfamily Amygdaloideae), whereas both Spiraeeae and Maleae are further away from Rubeae (subfamily Rosoideae) (Xiang et al., 2017). Interestingly, this phylogenetic relationship is relevant when comparing with our previous findings because CMBS infestations were found on species of tribe Maleae, including apple (Malus) and flowering quince (Chaenomeles), but not on blackberry and raspberry (Rubus), which are under tribe Rubeae (Xie et al., 2020).

Although the insect morphology suggested the unknown scale on Spiraea were CMBS, observational evidence still has limitations in its ability to identify species. For example, the azalea bark scale, a close relative of CMBS, is often mistaken as CMBS because the morphology is similar. Therefore, to confirm the identity, molecular approaches were used to verify that CMBS caused the infestation found on $S$. japonica and $S$. thunbergii.

\section{Materials and Methods}

Sample handling. Naturally occurring scale infestations (suspected to be CMBS) were found on C. americana (from Faulkner County, AR), S. japonica (from Faulkner County, AR), and $S$. thunbergii (from Concord, NC). The infested branches from different locations (Arkansas and North Carolina) were collected and stored in locking bags before shipping to the laboratory (Department of Biology, Texas A\&M University, College Station, TX) for further processing and analysis. Approximately 20 to 50 live nymphs (second instars) were collected using a fine pin or a fine brush from the infested twigs or branches of each tested plant species [crapemyrtle (control) and alternative hosts (Callicarpa and Spiraea)]. The CMBS nymphs on crapemyrtle were used as the control, and the infested plant material was collected from a colony maintained in a greenhouse in College Station, TX. Insects collected were used immediately or stored in a $-80^{\circ} \mathrm{C}$ freezer. DNA extractions were performed using the DNeasy Blood and Tissue Extraction Kit (Qiagen Inc., Valencia, CA).

DNA barcoding. The cytochrome oxidase I (COI) gene, a mitochondrial DNA commonly used for species identification in animals (Pentinsaari et al., 2016), was chosen to develop CMBS DNA barcodes. Previously reported universal primers have been used to amplify COI for several Acanthococcus species. Primer pairs reported by Simon et al. (1994). 

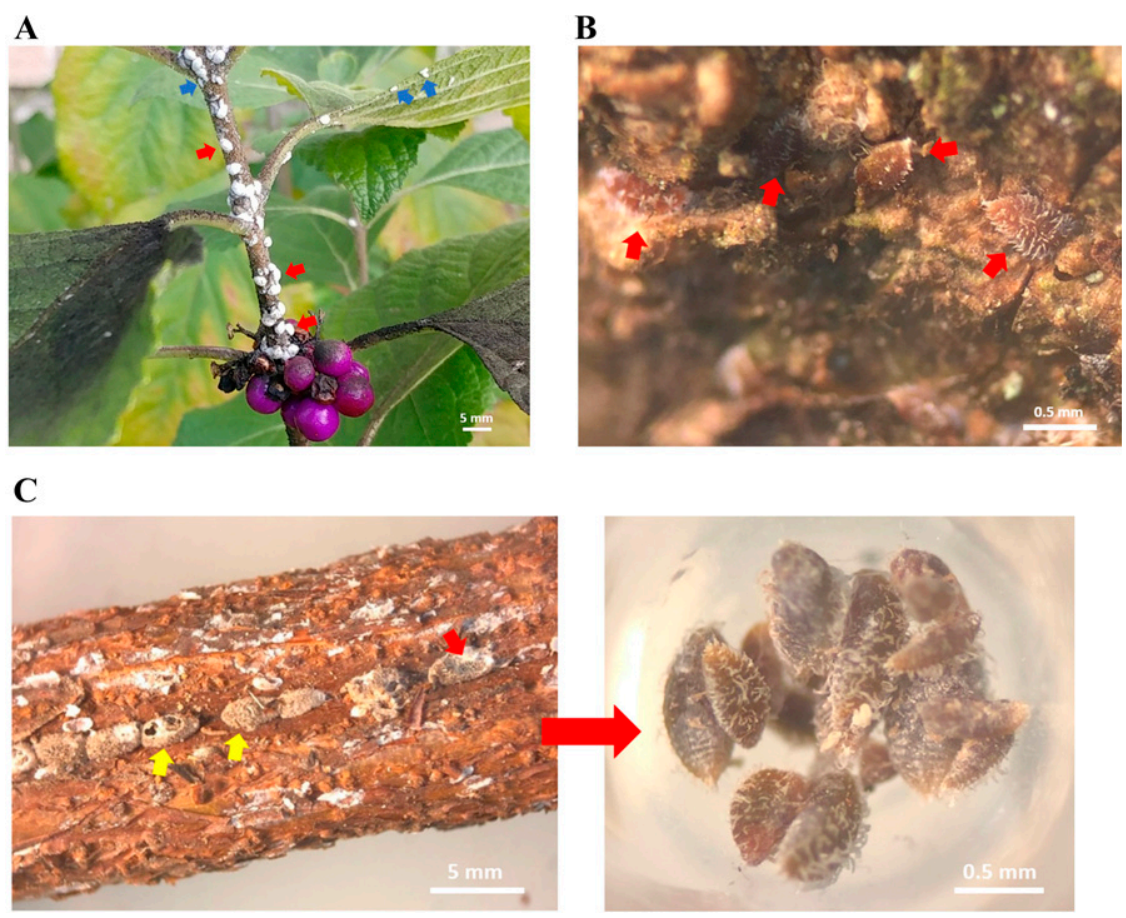

Fig. 1. Severe infestation of Acanthococcus lagerstroemiae on alternative hosts. (A) Callicarpa americana (red arrows: female ovisacs; blue arrows: male sacs). (B) Nymphs (red arrows) on Spiraea japonica. (C) Live nymphs (red arrows) collected from infested S. thunbergia for DNA extraction (yellow arrows: broken ovisacs).

CI-J-2183 (Jerry; 5' - CAACATTTATTTTGATTTTTTGG-3') and C1-N-2568 (Ben; 5' - GCWACWACRTAATAKGTATCATG-3') were used to amplify CMBS COI from two insect samples collected from $C$. americana (Brady et al., 2000; Schultz and Szalanski, 2019; Simon et al., 1994).

To amplify DNA sequences more specifically from the CMBS COI gene, primers based on the CMBS COI sequence (GenBank accession number: AB439520.1) were developed. The primer pair (forward: 5'-CCAGGATTTGGATTAATATCAC-3'; reverse: 5'-TGAACCAATTGATGATAGAG-3') was designed and successfully amplified CMBS COI sequences with lengths of $\approx 640 \mathrm{bp}$ in this study.

Polymerase chain reaction (PCR) and gel electrophoresis. The PCR program consisted of initially holding samples at $98^{\circ} \mathrm{C}$ for $30 \mathrm{~s}$, then 30 cycles of $98^{\circ} \mathrm{C}$ for $10 \mathrm{~s}, 51^{\circ} \mathrm{C}$ for $30 \mathrm{~s}$, and $72^{\circ} \mathrm{C}$ for $30 \mathrm{~s}$, followed by a final extension at $72{ }^{\circ} \mathrm{C}$ for $10 \mathrm{~min}$. The successful PCR amplifications were checked on a $1 \%$ agarose gel after electrophoresis and visualized using a Gel Doc E.Z. imaging system (BIO-RAD, Inc., Hercules, CA). The PCR products were purified and sent to a sequencing laboratory (Eton Bioscience, Inc., San Diego, CA) for direct sequencing in both directions.

Sequence alignment and phylogenetic tree. A 475-bp section of the COI sequence was used to analyze the relationship of CMBS from different hosts and two other closely related scale insects, Eriococcus azaleae and E. abeliceae. Four CMBS COI sequences obtained in this study have been deposited in GenBank, including a specimen collected on Lagerstromia from College Station, TX (GenBank accession number: MZ312637), a specimen collected on Callicarpa americana from Faulkner County, AR (GenBank accession number: MZ312638), a specimen collected on Spiraea japonica from Faulkner County, AR (GenBank accession number: MZ312639), and a specimen collected on $S$. thunbergia from Concord, NC (GenBank accession number: MZ312640). Nine previously reported CMBS COI sequences in Asia (China, Japan, and South Korea) and the United States (Tennessee and Texas) were used for comparisons with the sequences obtained in this study. A molecular phylogenetic tree was constructed using MEGA software based on the maximum likelihood analysis (Tanura-Nei model) (Kumar et al., 2018). The phylogeny test was conducted using the bootstrap method with the number of bootstrap replications set to 1000 .

\section{Results and Discussion}

The primer pair designed in this study successfully amplified CMBS COI sequences with lengths of $\approx 640 \mathrm{bp}$. Sequencing results revealed that amplicons from four insect samples had sequence lengths more than 600 bp. The BLAST results of a 475-bp section from each sample showed an identity score of $99 \%$ to $100 \%$ when aligned with CMBS COI sequences (GenBank accession number: KJ869281.1 or AB439520.1).

To study the relationship of CMBS collected from different geographical locations and plant hosts, we constructed a molecular phylogenetic tree to reveal the genetic relationship of CMBS relative to its two close relatives from the United States or Asia. According to the phylogenetic tree, CMBS and azalea bark scale are separated as two groups but share a common evolutionary origin compared with Eriococcus abeliceae Kuwana (Fig. 2). All the CMBS collected from either crapemyrtle or alternative hosts (Spiraea and Callicarpa) in the U.S. locations were grouped in a sister taxon compared with CMBS from the Asia location (Fig. 2), suggesting CMBS at different geographical areas might have been evolving differently (Baum, 2008).

Observational evidence suggests that the new infestations on alternative hosts may have originated from nearby, previously established CMBS infestations. Several incidents reported that the alternative host plants were initially healthy but became infested with CMBS when previously infested crapemyrtles were accidentally planted nearby. According to our laboratory observations and the previous description of the life history, CMBS remains sessile for most of its lifecycle (Wang et al., 2016). The developmental stages of a male CMBS consist of egg, two nymphal stages (first and second instar), three stages of pupa, and the winged adult stage. A female CMBS undergoes four major stages: egg, two nymphal stages (first and second instar), and adult stage. Although the adult male can fly and potentially travel between plants, the adult male is short-lived and does not feed or deposit eggs (Wang et al., 2016). Therefore, the dispersal of CMBS mainly occurs during the early stages of crawlers or soon after each molting. Long-distance dispersal of CMBS between different host plants may rely on wind, animals (such as birds or small mammals), and human activities. Similar phoretic dispersal has been reported for other scale insects, including armor scales 


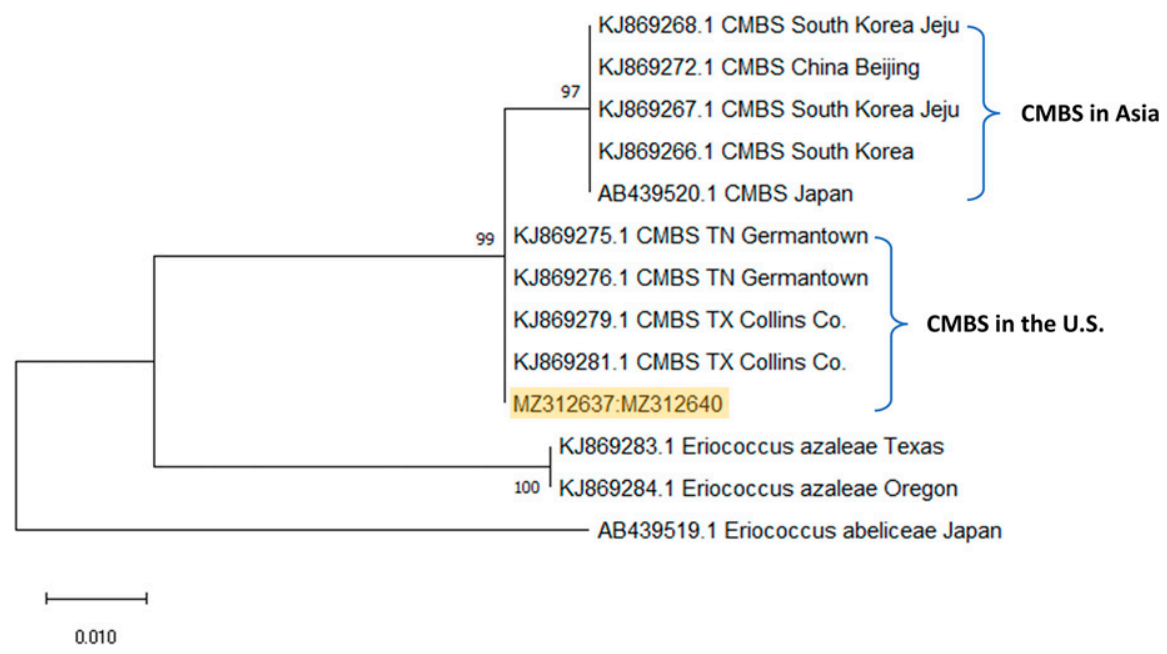

Fig. 2. The phylogenetic tree (maximum likelihood tree) indicates the genetic relationship of Acanthococcus lagerstroemiae, Eriococcus (Acanthococcus) azalea, and E. abeliceae from different geographical locations. Highlighted text (MZ312637:MZ312640) represents four GenBank accession numbers of four specimens of Crapemyrtle bark scale (CMBS) collected from alternative hosts or crapemyrtle at four different locations (Lagerstromia from College Station, TX: MZ312637; Callicarpa americana from Faulkner County, AR: MZ312638; Spiraea japonica from Faulkner County, AR: MZ312639; and S. thunbergia from Concord, NC: MZ312640).

(Magsig-Castillo et al., 2010), soft scales (Washburn and Frankie, 1981), and mealybugs (Klein et al., 1992; Reyne, 1954). Although the motility of CMBS by itself may be limited, the transmission of this insect between hosts is evident based on our results.

Our results confirm that CMBS is expanding not only its geographic range but also its host range. These findings bring the total number of CMBS hosts in Rosaceae to eight, making it one of the most prominent families hosting CMBS other than Lythraceae. According to the latest phylogeny study of Rosaceae, Chaenomeles, Malus, and Spiraea (confirmed CMBS host genera) were grouped under subfamily of Amygdaloideae (Xiang et al., 2017), in which at least 54 other genera were reported (Potter et al., 2007). Furthermore, Amygdaloideae includes many economically important crops such as apricot, almond, cherry, plum, and peach (Xiang et al., 2017). Therefore, further investigations are needed to evaluate the potential threat of CMBS to other valuable crops in the Rosaceae family, especially in the subfamily of Amygdaloideae.

\section{Literature Cited}

Baum, D. 2008. Reading a phylogenetic tree: The meaning of monophyletic groups. Nature Education $1: 190$

Brady, S.G., J. Gadau, and P.S. Ward. 2000. Systematics of the ant genus Camponotus (Hymenoptera: Formicidae): A preliminary analysis using data from the mitochondrial gene cytochrome oxidase I, p. 131-139. In: A.D. Austin and M. Dowton (eds.). Hymenoptera: Evolution, biodiversity and biological control. CSIRO Publishing, Collingwood, Victoria, Australia.

EDDMapS. 2021. Early detection \& distribution mapping system. Center for Invasive Species and Ecosystem Health. The University of Georgia. 4 Mar. 2021. <http://www.eddmaps.org/>. García Morales, M., B.D. Denno, D.R. Miller, G.L. Miller, Y. Ben-Dov, and N.B. Hardy. 2016. Eriococcus lagerstroemiae is now Acanthococcus lagerstroemiae (Kuwana, 1907) (Eriococcidae: Acanthococcus). 5 July 2021. <http://scalenet. info/catalogue/eriococcus\%20lagerstroemiae/ $>$.

Klein, R., D. Kovac, A. Schellerich, and U. Maschwitz. 1992. Mealybug-carrying by swarming queens of a Southeast Asian bamboo-inhabiting ant. Naturwissenschaften 79:422-423, https://doi.org/10.1007/BF01138577.

Kumar, S., G. Stecher, M. Li, C. Knyaz, and K. Tamura. 2018. MEGA X: Molecular evolutionary genetics analysis across computing platforms. Mol. Biol. Evol. 35:1547-1549, https:// doi.org/10.1093/molbev/msy096.

Magsig-Castillo, J., J. Morse, G. Walker, J. Bi, P. Rugman-Jones, and R. Stouthamer. 2010. Phoretic dispersal of armored scale crawlers (Hemiptera: Diaspididae). J. Econ. Entomol. 103:1172-1179, https://doi.org/10.1603/ec10030.

Pentinsaari, M., H. Salmela, M. Mutanen, and T. Roslin. 2016. Molecular evolution of a widelyadopted taxonomic marker (COI) across the animal tree of life. Sci. Rep. 6:1-12, https:// doi.org/10.1038/srep35275.

Potter, D., T. Eriksson, R.C. Evans, S. Oh, J. Smedmark, D.R. Morgan, M. Kerr, K.R. Robertson, M. Arsenault, and T.A. Dickinson. 2007. Phylogeny and classification of Rosaceae. Plant Syst. Evol. 266:5-43, https://doi. org/10.1007/s00606-007-0539-9.

Reyne, A. 1954. Hippeococcus: A new genus of Pseudococcidae from Java with peculiar habits. Zool. Meded. 32:233-257.

Schultz, P.B. and A.L. Szalanski. 2019. Hypericum kalmianum (St. Johnswort) confirmed as a new host of the crapemyrtle bark scale in Virginia, USA. J. Agr. Urban Entomol. 35:12-15, https://doi.org/10.3954/1523-5475-35.1.12.
Simon, C., F. Frati, A. Beckenbach, B. Crespi, H. Liu, and P. Flook. 1994. Evolution, weighting, and phylogenetic utility of mitochondrial gene sequences and a compilation of conserved polymerase chain reaction primers. Ann. Entomol. Soc. Amer. 87:651-701, https://doi.org/10.1093/aesa/ 87.6.651.

USDA. 2021. Agricultural Research Service, National Plant Germplasm System. National Germplasm Resources Laboratory, Beltsville, Maryland., Germplasm Resources Information Network (GRIN-Taxonomy)

Wang, Z., Y. Chen, M. Gu, E. Vafaie, M. Merchant, and R. Diaz. 2016. Crapemyrtle bark scale: a new threat for crapemyrtles, a popular landscape plant in the U.S. Insects 7:78, https://doi.org/10.3390/insects 7040078 .

Washburn, J. and G. Frankie. 1981. Dispersal of a scale insect, Pulvinariella mesembryanthemi (Homoptera: Coccoidea) on iceplant in California. Environ. Entomol. 10:724-727, https://doi.org/10.1093/ee/10.5.724.

Wrońska-Pilarek, D., B. Wiatrowska, and J. Bocianowski. 2019. Pollen morphology and variability of invasive Spiraea tomentosa L. (Rosaceae) from populations in Poland. PLoS One 14:e0218276, https://doi.org/10.1371/ journal.pone.0218276.

Xiang, Y., C.H. Huang, Y. Hu, J. Wen, S. Li, T. Yi, H. Chen, J. Xiang, and H. Ma. 2017. Evolution of Rosaceae fruit types based on nuclear phylogeny in the context of geological times and genome duplication. Mol. Biol. Evol. 34:262-281, https://doi.org/10.1093/ molbev/msw242.

Xie, R., B. Wu, H. Dou, C. Liu, G.W. Knox, H. Qin, and M. Gu. 2020. Feeding preference of crapemyrtle bark scale (Acanthococcus lagerstroemiae) on different species. Insects 11:399, https://doi.org/10.3390/insects11070399. 